\title{
Flipped learning convergence and innovation research based on task-driven teaching method---- A study of $C$ programming course in medical colleges
}

\author{
Lanzhen Chen ${ }^{a_{1} \star}$, Xiaopeng Li, Rudan Lin \\ School of Information Engineering, Gannan Medical University, Ganzhou 341000,China \\ adanrou_2006@qq.com
}

Keywords: flipped classroom, task-driven teaching method, C programming, feedback.

\begin{abstract}
With the flipped classroom widely use, its shortcomings during use gradually emerged. Author's research group explored the integration and innovation of $\mathrm{C}$ programming course flipped learning style based on the traditional teaching and modern educational characteristics, task-driven teaching method combined with the advantages of bi-directional to medical students. To a certain extent, the group improved the effect of teaching, avoided more widespread problems in flipped classroom. The members of research group explained the innovation of $\mathrm{C}$ programming classroom teaching in Gannan Medical University led by task-driven instructional design, flipping classroom, practice teaching, the implementation of negative feedback and other aspects. This article intends to contribute to the quality courses construction and disciplines construction of the $\mathrm{C}$ language programming.
\end{abstract}

\section{Introduction}

"Flipped classroom" can fully embodies the advantages of "blended learning, promotes the effective use of teaching resources and the research and development, conforms to the human cognitive law, helps to build a new type of relationship between teachers and students" and other features, are appreciated and welcomed by the teachers and students at all levels [1]. In the traditional teaching mode, students accept the teachers "knowledge transfer" was conducted in the classroom, while "the internalization of knowledge" was done outside the classroom by exercise. However, the "flipped classrooms" reformed the traditional model. Knowledge obtained by outside the classroom, the students used information technology, read the text teaching materials; the teachers provided short videos, targeted to specific problems, used the interpretation of online counseling to help students. "Knowledge internalization" is accomplished through interaction in the classroom, teachers by understanding students' learning difficulties, give effective guidance.At the same time, participators promote the absorption and internalization of knowledge by the organization more subject, multifaceted mutual exchanges. In this way, function of classroom teaching position has changed: it is not primarily used to gain knowledge, but to promote the internalization and application of knowledge. Classroom is no longer the default process, but a process of generation.

Due to "flipping the classroom" demand for network teaching and learning environment, as well as on teachers "hybrid" learning styles education idea and the requirements of teaching concept, design and arrangement of tasks before the class is particularly important. Mr.Hu Tian-Shuo, an online product marketing manager of New Oriental School have been carried out exploration, he met a number of issues and summed up a lot of valuable experience in the process of exploring the flipped classroom. The author's research group summarized the following outstanding issues by analyzing:

(1)Teaching and task design put forward higher requirements.

First is the nature of teacher preparation work had changed. On the one hand, the teacherneed to design appropriate instructional tasks allow students to complete. On the other hand, the teacher had to think about how to teach combine with teaching knowledge and their specialty characteristics.

Secondly, due to the limitations of classroom time, design aspects of the syllabus for teaching activities covered is not easy to do, that requires teacher think how to solve the potential omissions.

(2)Learning objectives have changed. 
Flipped classroom focus more on developing the problem-solving and understanding abilities of students. Therefore, the learning objectives from the traditional focus on grades and scores changed into a greater focus on improving of students themselves. For example, consider how to improve the independent learning of students? How to make the students study on a new step?

(3)Students' learning situation is difficult to grasp.

Flipping the classroom is a new challenge for many students. The first and foremost, teachers should admit the individual differences in student achievement levels, how to find the balance among teaching is a key issue. It's hard to track each student's class status, therefore, we cannot avoid a number of student don't like the ways of teaching, we also cannot avoid some student be there just to make up the number.

\section{Teaching of $\mathbf{C}$ programming course in author's school}

Gannan Medical University is locatedin a prefecture-level city in South-Central China. Like most medical undergraduate course colleges, the School gives priority to the development of medicine, and the science, engineering, liberal arts, management, law and other professional, multi-disciplinary coordinated development. However, as an independent set of undergraduate course colleges of western medicine, because of the periodic characteristics of interdisciplinary professional development, the science and engineering foundation education in Gannan Medical University is relatively weak.

At present, the school offered programming courses, hoping to promote the cultivation of students' ability to analyze and solve problems, and develop logical thinking and rigorous scientific style by learning lessons. However, due to the medical students are lacks of comprehensive and systematic learning as a comprehensive university student foundation study, direct learning computer programming courses will be very difficult.In particular, the syntax of the $C$ programming language for students are not exposed to programming based, the course's content is very boring on syntax rigor, and getting started is difficult. The existing teaching contents did not reflect career oriented and lack of university-enterprise (hospital) cooperation. The project driven teaching arrangement and the program design course content disconnected with the future work, many students get bored in the course, and there is no motivation for them to go on their study.

\section{Problem-solving hypotheses and theoretical foundation}

The research group encouraged students learning tasks, targeted for learning and related data, to set up the database by the existing objective task allocation (Use task-driven teaching method).

\subsection{About the "task-driven teaching method"}

Task-driven teaching method is a kind of based on constructivism learning theory, which previously dominated by imparting knowledge of traditional teaching concepts to problem solving, task-oriented multi-dimensional interactive teaching philosophy. Constructivist learning theory emphasizes that students learning activities must be combined with a task or a problem to explore questions to guide and maintain the learner's learning interest and motivation, creating a real teaching and learning environment for students with the real task of learning, so that students have a learning initiative.

Students learning is not only the transfer of knowledge from outside to the inside, but also actively construct their own knowledge.The students enrich their knowledge and ability by the interaction of new experience and original knowledge [2].

\subsection{Prepare for flipped classroom}

(1) Teaching in small classes and group management, each assigned a student turns to manipulate.

(2) Open the cloud database, assign students to find pre-learning sections of knowledge, enrich the learning materials for libraries, and upload to the public network.

(3)The teachers make instructional videos and courseware and upload teaching resources for students to learn. 
(4)The teachers prepare several questions for flipping the classroom, and assign tasks with the task-driven teaching.

(5)The teachers categorize and prepare tips according to students' preliminary discussion on problems.

\section{3 (Negative) feedback teaching regulation}

(1) The teacher collected and integrated feedback of studentsfrom practice class, establish course feedback database.

(2) The teachers index the repeat and representative feedback problems by chapter, list the key word and provide query retrieval functions.

(3) The teachers formulate the corresponding knowledge of video and PPT according to the feedback of students learning situation, design interactive questions for flipped classroom, and enrich the presentation content.

\subsection{Teaching evaluation stands out four favorable goals.}

The final evaluation standard of flipped classroom or task-driven teaching method are both mean the teaching methods and teaching improved the students ' enthusiasm and effectiveness as the main evaluation criteria. In teaching methods, teachers should pay attention to reflect four "benefits" principle, to exert the principal role of students, to develop students ' critical-thinking skills, to cultivate students' innovative spirit, to the tap students' individual potential.

\section{Innovation implementation}

The research group was applied "task-driven method" to computer program design course teaching in the process of implementing flipped classroom teaching of $C$ language programming. The members of the group select the appropriate program designed teaching process cases and flipped the classroom teaching plan formulation by investigating the research of carding process with the pharmaceutical industry. Teachers cultivate the students' programming problem solving skills, team spirit and also make full use of the existing disciplines platform, in order to improve the learning center program design course resources and realize the organic regulation to the teaching of this course by using the bridge effectively.

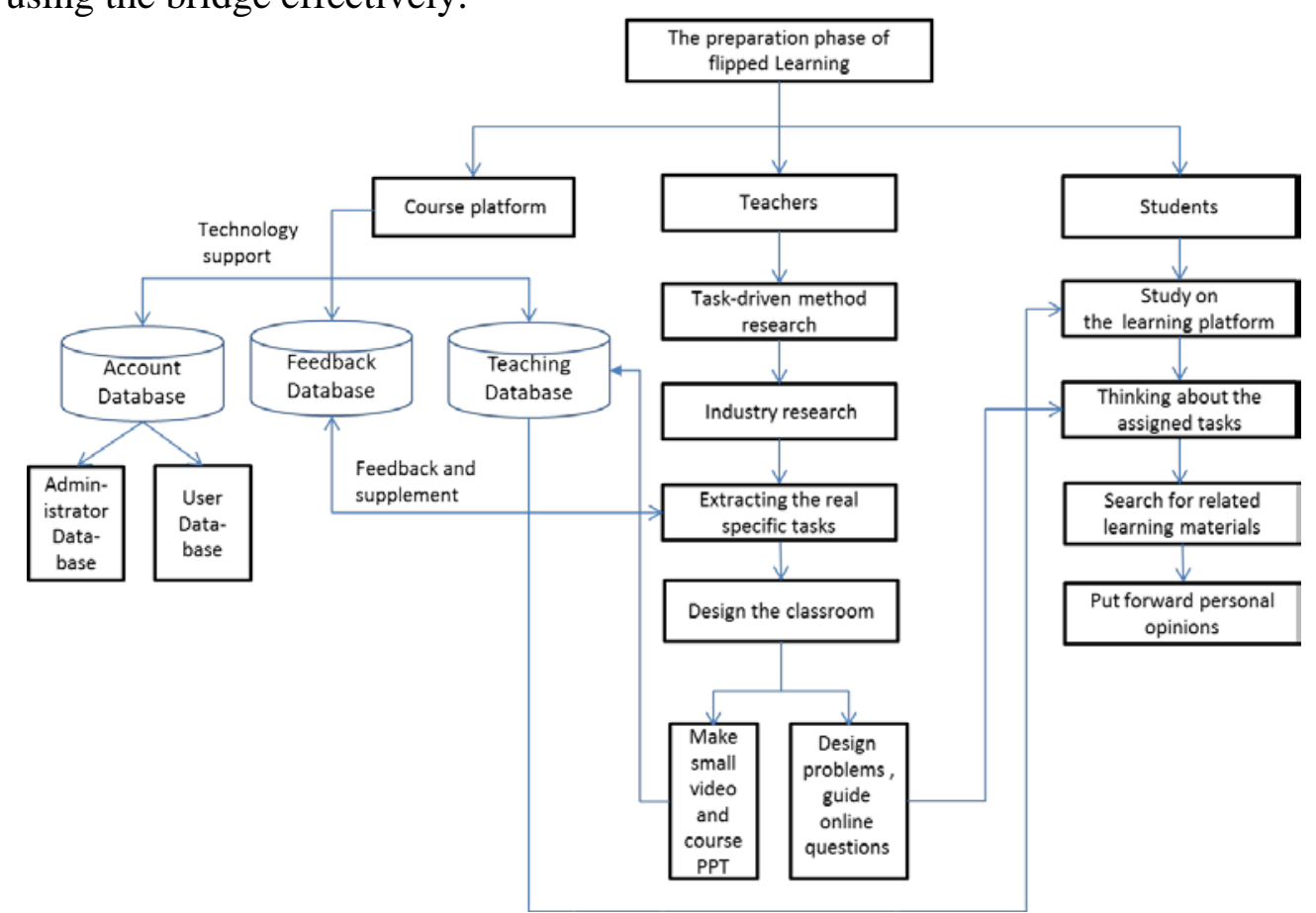

Figure 1: Flowcharts of the preparation phase in flipped learning

The members of research group focus on "flipped learning" as the center, teaching is divided into three phases: the preparation phase, the flipping the classroom phase, and the perfecting the feedback. Class preparation is the key of construction, the other two phases based on this implementation of the 
flipped classroom integration and innovation. Mainly involves three aspects: teachers, students and the course platform. Innovative thinking and the implementation of the reform path of the preparation phase in flipped learning as shown in the following Figure1:

Teachers pay attention to the basic principle of knowledge internalization and the practical application of knowledge in the process of turning, flipping the classroom to maximize its effectiveness.

\section{Acknowledgements}

This work was financially supported by Colleges and universities teaching reform research projects in Jiangxi province (No. JXJG-12-12-03) in 2012; College of Humanities and social science research projects in Jiangxi province (No. SH1302) in 2013.

\section{References}

[1] He Ke-kang. Essentially "flipped classroom" to see "flipped classroom" future development in China [J]. Educational Research, 2014,07: 5-16.

[2] Interactive Encyclopedia, task-driven pedagogy .http: //www.baike.com/wiki/ task-driven teaching method \& prd = so_1_doc. 